Send your letters to the editor, British Dental Journal, 64 Wimpole Street, London W1G 8YS E-mail bdj@bda.org

Priority will be given to letters less than 500 words long. Authors must sign the letter, which may be edited for reasons of space.

\section{Burnout syndrome}

Sir, T. M. Johnson (BDJ 2006; 200: 600) states inter alia: 'The statement "General Dental Practitioners have a higher risk of suicide than the general population" is not supported by the available evidence, as documented by Alexander, in his excellent review of the literature published in 2001, nor by any further statistically significant evidence I have been able to find.'

Roger E. Alexander's paper (available at http://jada.ada.org/cgi/content/ full/132/6/786) is based in the USA. In Alexander's review, Steven Stack's paper (1996) Suicide among dentists: A national study, also USA based - which concluded that, even after controls for associated covariates, dentists are 6.64 times more likely than the general populace to commit suicide - is questioned and dismissed as flawed.

In my view there is plenty of evidence to suggest that dentists in the UK have a higher than average risk of suicide.

For instance: 'Several occupational groups in the United Kingdom appear to have considerably elevated risk of suicide. These include, for example, farmers, doctors (especially females), dentists, pharmacists, veterinary surgeons, and female nurses. ${ }^{1}$

Proportional mortality ratios (PMRs) compare the proportion of deaths in an occupation from a specific cause to the proportion of deaths from that cause in all occupational groups. A PMR of 100 for a particular occupation indicates no difference in the proportion of deaths from that particular cause. A PMR of 50 indicates only half the proportion of deaths.

'From 1982-1987, male vets showed the highest PMR from suicide having more than three times the average male suicide risk. However, this figure comes from a total of 17 suicides over the six years. From 1991-1996 the number of suicides dropped to nine, resulting in the second highest PMR (349) of those analysed. Dental practitioners are now seen as a higher risk group as the figure is based on a larger number of suicides and is therefore more reliable.

'Male dental practitioners have become the group with the highest significant suicide risk in the time period 1991-1996 (2.49 times the average), during which there were 25 suicides in this group. ${ }^{2}$

'PMRs for dentists, pharmacists and veterinarians have been increased in several previous studies. Differences in these occupations in Scotland were not statistically significant. In 16 to 45year-old men, dentists had ratios with confidence intervals for men aged a PMR of 128 (95\% CI 26-374), pharmacists a PMR of 43 (95\% CI 1-238) 16-45 years, 19811999 and veterinarians a PMR of 293 (95\% CI 80-749). In 46 to 64-year-old men, the PMR for dentists was 235 (95\% CI 76-548), 118 for pharmacists (95\% CI 14-242) and 301 for veterinarians (95\% CI 36-1,088). ${ }^{3}$

On the bright side, dentists' death rates from other causes are lower, and on average they live several years longer than the general population. ${ }^{4}$

M. Preston

Essex

1. University of Oxford Centre for Suicide Research.

2. Kelly S, Bunting J. Trends in suicide in England and Wales, 1982-96. Population Trends 1998; 92.

3. Stark C. Male suicides in Scotland. Health Statistics Quarterly 2006.

4. http://www.straightdope.com/columns/010420.html doi: 10.1038/sj.bdj.4813900

\section{Join US}

Sir, there are a great number of dentists, both active and retired, who had the privilege of being educated, and possibly working at, Guy's Hospital Dental School.

We have been saddened at the loss of identity which has taken place as the result of the merging of similar institutions into the King's Dental Institute.

In the same way that famous regiments and campaigns have founded their own associations, we feel that now is the time for Guy's men and women to establish their own distinctive group. Perhaps a provisional title of 'Guy's Dental Alumni Association' may be regarded as a working title.

We invite those present students at Guy's who have a strong feeling of allegiance to such an historic dental institution, which has recorded dental lectures as long ago as 1799, to consider joining us.

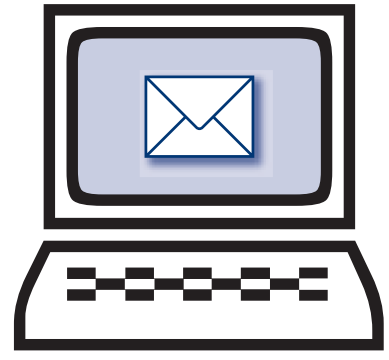

As a first step, could those interested in being part of this project write or email, giving their contact details, so that we can establish a database.

Contact: Brian Lux, 49 Abbey Road, Llandudno, Conwy, LL30 2EH

Email: brian@luxb.freeserve.co.uk

B. Lux, D. Forman, D. Kay, J. VanDen Burg, A. d'Arcy Fearn

By email

doi: 10.1038/sj.bdj.4813901

\section{Mocha and muffins}

Sir, I am sure all will have noticed the unrelenting spread of the coffee shop. These establishments are now the haunt of many a young professional at lunchtimes. I, like many of this cohort, only recently began to frequent these coffee houses, previously having a reasonably low refined carbohydrate lunch (but not finding the draw of the mocha and blueberry muffin too strong). I believe the highly cariogenic nature of the produce sold by these establishments could lead to a ticking time bomb of caries in this group who previously experienced a relatively low caries rate.

It is quite disappointing to note that only one major coffee shop provides a sugar free flavouring.

D. Ellis

Manchester

doi: 10.1038/sj.bdj.4813902

\section{Delphi definitions}

Sir, the Delphi technique has a number of pitfalls, and I fear Kearney-Mitchell et al. (BDJ 2006; 200: 509-512) have been caught by a tricky one, how to define consensus.

Kearney-Mitchell et al. asked respondents to rate "child with caries in deciduous dentition' on a scale from 1 (definitely no need for referral) to 9 (definite need for referral). The final round of ratings produced a median of 7 with interquartile range of 6 to 9 . Thus at least $75 \%$ of respondents gave a score of 6 or above, ie towards the referral end of the scale. Despite this substantial majority, the researchers rejected this criterion for referral. This appears to conflict with both their title that proclaims 'the development 
of a consensus' and also their text that states that their sample dentists were able to agree criteria for referral. Or perhaps they mean that the dentists agree with each other, just not with the research team? J. Woolgrove

Bromley

doi: 10.1038/sj.bdj.4813903

\section{Local limits}

Sir, further to the letter by N. Foot of Newbury (BDJ 2006; 200: 599), I write to highlight 'one good scientific reason' why local anaesthetic is supplied in $2.2 \mathrm{ml}$ cartridges in the UK.

Two per cent lignocaine (AKA lidocaine) with 1:80,000 adrenaline is currently recognised as the 'gold standard' dental anaesthetic in the UK. ${ }^{1}$ The maximum recommended dose of lignocaine is 4.4 mg per kilogram, with an absolute ceiling of $300 \mathrm{mg}$. Two per cent lignocaine translates into $20 \mathrm{mg}$ per $1 \mathrm{ml}$, so that the standard UK presentation cartridge of 2.2 $\mathrm{ml}$ contains $44 \mathrm{mg}$ lignocaine.

Conveniently therefore, a $2.2 \mathrm{ml}$ cartridge of 2\% lignocaine with 1:80,000 adrenaline contains the maximum dose of lignocaine for $10 \mathrm{~kg}$ of body mass. One tenth of a cartridge contains the maximum dose per kilogram. This simple rule allows the surgeon to readily see that they are administering the drug within the maximum dose. The maximum ceiling of $300 \mathrm{mg}$ translates as just under seven cartridges (6.8 to be precise).

Adrenaline in the concentration $1: 80,000$ is equivalent to $12.5 \mu \mathrm{g}$ per $1 \mathrm{ml}$. The $2.2 \mathrm{ml}$ cartridge therefore contains $27.5 \mu \mathrm{g}$ of adrenaline. Keeping to the 'one $2.2 \mathrm{ml}$ cartridge per $10 \mathrm{~kg}$ body mass rule' keeps adrenaline within recommended limits also.

\section{J. V. Williams}

Cambridge

1. Meechan J G, Robb N D, Seymour R A. Pain and anxiety control for the conscious dental patient. Oxford, 1998.

doi: 10.1038/sj.bdj.4813904

\section{Lethal consequences}

Sir, the editorial by Martin on antibiotic prophylaxis for the prevention of infective endocarditis (IE) in patients with cardiac disease undergoing dental procedures reflects poorly on the dental profession. ${ }^{1}$

It reveals an ignorance of this devastating condition and an inability to learn from previous experience. Moreover, it is disappointing that he prefers to turn to laboratory specialists for advice on antibiotic prophylaxis for patients at risk of $\mathrm{IE}^{2}$ rather than accept the recommendations of the experienced body of cardiologists and cardiac surgeons in the UK, Europe and the USA. ${ }^{3-5}$ To say that the link between IE and dentistry is tenuous and much over-emphasised is naïve, untrue and mischievously misleading. The comments that dentists 'do things to prevent IE because of emotion rather than science' suggests a poor understanding of the pathogenesis of IE and a major underestimate of the intelligence of dentists in clinical practice in the UK. Furthermore, his statement that the sensible dental practitioner who gives prophylaxis in those 'at-risk' patients is 'largely based on the fear of medicolegal action' is an insult to such professionals.

If Martin was aware of the potentially lethal consequences that occur as a result of the vasculitic and embolic complications of IE, he perhaps would not be dismissive of the need to protect those patients at risk who put their trusts in our professionalism and expertise. Although the extracardiac complications involving the kidneys, gastrointestinal and central nervous systems are very serious, the cardiac complications are particularly life-threatening because of their local destructive effects. Valvular destruction causing severe aortic or mitral regurgitation and cardiac failure, aortic root abscesses, myocarditis and cardiac abscesses, false aneurysms and fistula formation between cardiac chambers and aorta are difficult to treat and carry a poor prognosis despite surgical intervention.

Patients who develop IE go quickly from being healthy to becoming very sick and require intensive intravenous antibiotic therapy for a prolonged period in hospital. Much of this time will be in an intensive care unit especially when major organ involvement occurs. Unfortunately, a large number of patients will require cardiac surgery to replace a valve(s), repair a fistula, resect an aneurysm or replace the aortic root and surgery frequently carries a high post-operative morbidity and mortality despite using powerful parenteral antibiotics in large doses for a prolonged period in-hospital. Patients with prosthetic valve IE are more difficult to treat than those with infection on native valves, usually require further cardiac surgery to remove the infected prosthesis and have the highest morbidity and mortality. IE is still associated with a mortality rate of 30\% despite antibiotic treatment and surgery.

Because IE is still such a life-threatening condition, every effort to prevent it should be made. Greater awareness of the seriousness of the condition and vigilance to try and prevent it is required rather than the rationing of antibiotic prophylaxis for convenience sake. Bacteraemia is usually a prerequisite for the development of IE and patients with certain cardiac abnormalities appear to be more likely to develop infected vegetations on or close to the anatomical defect. In such 'at-risk' patients, antibiotic prophylaxis should be given to try and deal with the bacteraemia created by whatever instrumentation that is responsible. It is irrational and reckless in our view not to give antibiotic prophylaxis to, for example, patients who have mitral valve prolapse and regurgitation or a bicuspid aortic valve and who are undergoing dental work. The recommendations by BSAC are woefully inadequate, were not created as a result of consultation with the British Cardiac Society and are at odds with the national and international guidelines on antibiotic prophylaxis for the prevention of IE.

Martin's editorial is entitled 'victory for science and common sense'. The science of pathology has clearly demonstrated the mechanism of the formation of vegetations in IE and yet he chooses to ignore it presumably because a randomised clinical trial has not been published which shows benefit in favour of those receiving prophylaxis over those not given preprocedural antibiotics. This is unlikely to happen because of the unethical nature of the research. As for common sense, this is sadly lacking in this editorial and in the BSAC recommendations but hopefully will be shown by the majority of dentists in the UK who will follow the UK/European Society of Cardiology/American Heart Association \& American College of Cardiology Guidelines and continue to provide antibiotic prophylaxis for all their patients deemed to be at risk of IE because of existing cardiac pathology.

D. R. Ramsdale, L. Morrison, M. D. Palmer,

B. Fabri

Liverpool

1. Martin M. A victory for science and common sense. The new guidelines on antimicrobial prophylaxis for infective endocarditis. Br Dent J 2006; 200: 471.

2. Gould FK, Elliott TS J, Foweraker J et al. Guidelines for the prevention of endocarditis: report of the Working Party of the British Society for Antimicrobial Chemotherapy. J Antimicrob Chemother 2006; 57: 1035-1042.

3. Ramsdale D R, Turner-Stokes $L$ on behalf of the Advisory Group of the British Cardiac Society Clinical Practice Committee and the RCP Clinical Effectiveness and Evaluation Unit (2004). Prophylaxis and treatment of infective endocarditis in adults: a concise guide. Clin Med 2004; 4: 545-550.

4. The Task Force on Infective Endocarditis of the European Society of Cardiology. Guidelines on Prevention, Diagnosis and Treatment of Infective Endocarditis. Executive Summary. Eur Heart J 2004; 25: 267-276.

5. Dajani A, Taubert $K$, Wilson W et al. Prevention of bacterial endocarditis. Recommendations by the American Heart Association. Circulation 1997; 96: 358-366

doi: 10.1038/sj.bdj.4813905 


\section{Defying explanation}

Sir, neither the British Congenital Cardiac Association (BCCA) nor the British Cardiovascular Society (BCS) share your editorial author's ${ }^{1}$ enthusiasm for the new guidelines for the prevention of endocarditis published by the British Society for Antimicrobial Chemotherapy (BSAC). ${ }^{2}$ In our view the changes to the guidelines are neither based upon science nor common sense and we do not commend these proposed changes to our members or the public.

If there was sound evidence to suggest that the risk of anaphylaxis outweighs the possible benefit of antibiotic prophylaxis, then the correct recommendation would be to abandon antibiotic prophylaxis. The BSAC do not recommend that, so logic suggests that they must be of the opinion that invasive procedures known to induce bacteraemia do indeed pose a risk for certain patients. To recommend prophylaxis only in patients with previous endocarditis, prosthetic valves or implanted conduits, excluding those with high velocity intracardiac jets known to be at high risk of endocarditis (such as mitral regurgitation or ventricular septal defect) defies logical explanation. To go on to recommend prophylaxis in a very restricted group of patients even for dental procedures which do not involve gingival damage and are therefore unlikely to induce significant bacteraemia similarly defies logic.

We recognise that current guidelines from the UK, Europe and North America are based upon broad consensus rather than hard evidence. To change these recommendations on the basis of views of one small group (the BSAC) rather than science is likely to simply repeat the mistakes of the past. The BCCA and the BCS wrote to the BSAC setting out the reasons for our disagreements with their new recommendations well in advance of publication but our views were dismissed. To publish new national guidelines which fail to take into account the consensus of the UK cardiologists' national professional body seems most unwise and is likely to cause much confusion in clinical and medicolegal practice.

We are pleased that the National Institute for Clinical Excellence (NICE) has agreed to report on prevention of endocarditis. We strongly recommend that no change in current practice should take place until NICE have published on the matter.

\section{J. L. Gibbs, M. Cowie, N. Brooks}

1. A victory for science and common sense. The new guidelines on antimicrobial prophylaxis for infective endocarditis. Br Dent J 2006; 200: 471.
2. Guidelines for the prevention of endocarditis: report of the working party of the British Society for Antimicrobial Chemotherapy. J Antimicrob Chemo Advanced Access 2006.

Dr Mike Martin responds to the above two letters: I would like to thank Drs Gibbs, Ramsdale and colleagues for their replies to my editorial. ${ }^{1}$

There is one fact that all parties can agree upon and that is infective endocarditis (IE) is a devastating disease for those who contract it. It certainly does wreck lives and can cause serious problems for the carers of people who have the disease. The gravity of this disease is therefore not lost on anyone who writes, or makes any kind of recommendations about antibiotic prophylaxis.

I am sure that the British Society of Antimicrobial Prophylaxis (BSAC) working party on IE have examined all the evidence available to them, including that presented by Ramsdale, Gibbs and colleagues. ${ }^{2}$ All branches of medicine move forward based on evidence and unfortunately I see no new evidence presented by your correspondents. Well respected clinicians in this field have thoroughly reviewed the clinical and scientific evidence and have consistently provided evidence that the link between dentistry and IE is tenuous. ${ }^{3,4}$ Even in the civil courts, where the standard of proof is on 'the balance of probabilities' (ie 51\%), it is very difficult to prove an association between dental treatment and IE. ${ }^{5}$ In addition, very many patients who are unaware of their predisposition to IE receive dental treatment every day and do not contract this disease; thankfully it is very rare.

The evidence that a single dose of amoxicillin works prophylactically is also problematical. A Cochrane review of the literature also failed to demonstrate any efficacy. ${ }^{6}$ The original paper on antimicrobial prophylaxis and IE by Northrop and Crowley reduced dentallyinduced bacteraemias from $12.8 \%$ to $4 \%$, however the methodology and the statistical tests used in this paper are questionable and the conclusions not justified. Bacteraemias generated from dentistry probably last for circa 20 minutes. Amoxicillin primarily works on dividing bacteria, a situation that does not apply to bacteraemias. The evidence that has accumulated from animal models of infective endocarditis show that initially bacteria present on the heart divide slowly with mean generation times of 12-24 hours, when there would be little amoxicillin present in the blood stream. Thus the mode of action of amoxicillin could be to hinder or prevent attachment of bacteria to platelets or fibrin, or perhaps to aid phagocytosis of the bacteria. Even in animal models prophylaxis does not completely prevent IE and there are well documented failures of amoxicillin prophylaxis in patients. ${ }^{7}$ Thus there is considerable room for doubt that a single dose of prophylactic antibiotic works reliably in preventing IE.

If the advisory bodies quoted by your correspondents wish to challenge the BSAC working party on IE they must do so on the basis of scientific evidence. The BSAC working party did consider completely abolishing antibiotic prophylaxis for dental procedures, I personally wish they had taken this step. ${ }^{2}$ I am pleased to hear that NICE is to examine the relationship between antibiotic prophylaxis and dentistry, I am confident that they will agree with the $B S A C$ recommendations.

Perhaps there are active steps that cardiologists and dentists could take to negate any risk of IE from dental operations. Cardiologists could advise persons at risk of IE to get dentally fit and thus prevent constant low grade bacteraemias. ${ }^{8}$ Dentists could also reduce bacteraemias by judicial use of topically applied antiseptics which are known to reduce bacteraemias. ${ }^{9}$ These steps would prevent the high use of antibiotics in dentistry, where almost one third of all prescriptions are for prophylactic purposes. ${ }^{10}$

1. Martin MV. A victory for science and common sense The new guidelines on antimicrobial prophylaxis for infective endocarditis. Br Dent J 2006:200: 471.

2. Gould FK, Elliott TSJ, Foweraker Jet al. Guidelines for the prevention of endocarditis: report of the British Society for Antimicrobial Chemotherapy. J Antimicrob Chemother 2006;57: 1035-1042.

3. Durack D T. Prophylaxis of infective endocarditis. In Mandell G L, Bennett J E, Dolin R (Eds). Principles and practice of infectious disease. Vol 1, pp 1044-1051. Philadelphia: Elsevier, Churchill Livingstone, 2005.

4. Strom B L, Abutyrn E, Berlin J A et al. Dental and cardiac risk factors for infective endocarditis. $A$ population based case-controlled study. Ann Intern Med 1998; 129: 76-769.

5. Martin MV, Butterworth M L, Longman LP. Infective endocarditis and the dental practitioner; a review of 53 cases involving litigation. Br Dent J 1997: 182: $465-468$.

6. Oliver R, Roberts $G J$, Hooper L. Penicillins for the prophylaxis of bacterial endocarditis. Cochrane Database Syst Rev 2004

7. Longman LP, Martin MV, Smalley JW. One and two dose of cephradine in the prophylaxis of experimental streptococcal endocarditis. J Antimicrob Chemotherap 1987;20: 557-562.

8. Roberts $G$ J. Dentists are innocent! 'Everyday' bacteraemias is the real culprit: a review and assessment of the evidence that dental surgical procedures are a principal cause of bacterial endocarditis in children. Paediatr Cardiol 1999: 20: 317-325.

9. Lockhart PB. An analysis of bacteraemias during dental operations. A double-blind placebo controlled study of chlorhexidine. Arch Intern Med 1996: 156: 513-520.

10. Palmer NA O, Pealing R, Ireland RS, Martin MV. A study of prophylactic antibiotic prescribing in National Health Service general dental practice in England. Br Dent J 2000: 189: 43-46.

doi: 10.1038/sj.bdj.4813906 


\section{A reassuring experience}

Sir, we write in response to Dr Hussain's letter (BDJ 2006; 200: 540) which highlights the challenges of acting in the best interests of children when we have concerns about their possible abuse and neglect. We write as a team comprised of dentist, dental nurse, receptionist and dental health educator, with very recent experience of a similar case which may offer some encouragement.

A 10-year-old boy was referred to our salaried service by his GDP for restoration of carious teeth and two fractured incisors, traumatised on separate occasions some months previously. He gave an adequate accidental explanation for the injuries, confirmed by his mother. He had presented for treatment at the time of injury but had been anxious and unable to cooperate.

When scheduling the next appointment our receptionist noted a strong smell of alcohol as his mother handed over her appointment card at arm's reach. At subsequent appointments with both the dentist and dental health educator the same was noted. On each occasion we were careful to observe that his mother appeared sober and that the family were travelling home by taxi, not driving. There were no other features of concern - the boy was clean, appropriately dressed, oral hygiene had improved following instruction and there appeared to be a warm supportive parent-child interaction which contributed to his rapid acclimatisation to dental treatment.

We were aware of recent policy changes, particularly in response to the Victoria Climbié Inquiry, ${ }^{1}$ which encourage health professionals to intervene early to promote the welfare of vulnerable children. ${ }^{2}$ Advice was obtained by telephone from our local child protection nurse adviser. It was agreed that these findings did not indicate immediate referral to social services. However, we were advised that parental alcohol abuse would have an impact on the child's welfare and we should raise the issue with his mother and encourage her to seek help from her own general medical practitioner or the child's school nurse. The dentist did so at the next visit, accompanied in surgery by the dental nurse, while the child received toothbrushing instruction with the dental health educator in an adjacent room. It was a daunting task but our fears proved unfounded. His mother was embarrassed and tearful but neither angry nor aggressive. She readily admitted her problem. She agreed to see her doctor and to allow us to phone him and share information. We all tried to communicate with empathy and to make it clear that we welcomed the family to return. They have done so on three further occasions. At the last two visits she looked well and, for the first time, did not smell of alcohol. We dare to hope that perhaps this conversation may have been a turning point for this particular family. Perhaps colleagues will be somewhat reassured by our experience that such action need not inevitably lead to conflict.

Your readers will be aware from articles in recent editions of the journal that further information on child protection is now available specifically for the dental team as an open access website www.cpdt. org.uk and in a handbook sent to NHS practices in England and Scotland. ${ }^{3}$ This includes advice on how to contact local advisers and access training.

J. C. Harris, A. Ford, M. Smith, P. Barnes By email

1. Publication no. CM 5730. The Victoria Climbié Inquiry Report. London: The Stationery Office, 2003. www.victoria-climbie-inquiry.org.uk

2. Working together to safeguard children. London: Department for Education and Skills, 2006. www.everychildmatters.gov.uk

3. Harris J, Sidebotham P, Welbury R et al. Child protection and the dental team: an introduction tosafeguarding children in dental practice. Sheffield: COPDEND, 2006. www.cpdt.org.uk

doi: 10.1038/sj.bdj.4813907

\section{Cascade training}

Sir, the new guidance from the

Resuscitation Council (UK), Medical emergencies and resuscitation - Standards for clinical practice and training for dental practitioners and dental care professionals poses an interesting question. Who is to provide the recommended training in the use of an Automated External Defibrillator (AED)?

Immediate Life Support courses (which include the use of an AED) are not currently widely available for the dental team. It is also difficult to imagine that the existing CPR training providers (Resuscitation Council, Resuscitation Training Officers) will be in a position to cope with the greatly increased demand.

The Dental Sedation Teachers Group (DSTG) and The Society for the Advancement of Anaesthesia in Dentistry (SAAD) have endorsed the new guidance document and we particularly support the concept of designated trainers within the dental practice providing 'cascade' training. In our opinion, this is the only way it will be possible to provide Immediate Life Support training on the necessary scale.

P. Coulthard, D. Craig

By email

doi: 10.1038/sj.bdj.4813908 